\title{
THE EFFECT OF SOME ANTIBIOTICS ON ENDOGENOUS PHOSPHOLIPASE ACTIVITY IN RAT LIVER
}

\author{
Jun Matsumoto ${ }^{\dagger}$ and Kunihiko Saito* \\ Department of Medical Chemistry, Kansai Medical School \\ Moriguchi, Osaka 570, Japan
}

(Received for publication February 25, 1984)

\begin{abstract}
In relation to a previous paper (J. Antibiotics 32: 734 739, 1979), the effect of some antibiotics on endogenous phospholipid degradation of rat liver was investigated by slice and perfusion techniques. Polymyxin B inhibited this degradation most strongly, benzylpenicillin, chloramphenicol and peplomycin inhibited moderately, and carbenicillin, cephaloridine and streptomycin did not inhibit. Tetracaine and ethylenediaminetetraacetic acid, which are not antibiotics, also showed inhibitory effects.

The results strongly suggest that besides their usual antibiotic actions, some antibiotics may participate in endogenous phospholipid metabolism and biomembrane functions of host cells.
\end{abstract}

Under hypoxic conditions, cells of various organs, such as rat liver ${ }^{1)}$, and kidney ${ }^{2)}$, are injured and die, possibly owing to the endogenous phospholipase activity, phospholipid degradation and dysfunction of biomembranes.

In previous papers ${ }^{3,4)}$, the effect of some antibiotics on phospholipase activity in vitro was reported. In this paper, to more closely simulate an in vivo system, slice and perfusion techniques were employed in which the effect of 7 antibiotics and 2 other compounds on endogenous phospholipase activity of rat liver was examined. Some of them were found to inhibit endogenous phospholipid degradation.

The results strongly suggest that some antibiotics participate in endogenous phospholipid metabolism and biomembrane function of host cells in addition to their usual antibiotic actions.

\section{Materials and Methods}

The antibiotics tested were as follows: benzylpenicillin potassium, streptomycin sulfate (Meiji), carbenicillin disodium, polymyxin B sulfate (Pfizer-Taito), cephaloridine (Shionogi), chloramphenicol sodium succinate (Sankyo), peplomycin (pepleomycin) sulfate (Nippon Kayaku). Tetracaine hydrochloride (Kyorin) and ethylenediaminetetraacetic acid (EDTA) disodium were also used. The heattreated phospholipase $\mathrm{A}_{2}{ }^{5}$ ) was free from protease, phosphodiesterase, AMPase activities and had a specific activity of 38.5 for egg yolk phosphatidylcholine. Melittin, No. M-7129 from bee venom, was obtained from Sigma. This is a membrane-active peptide and stimulates the activity of an endogenous as well as an added phospholipase $\mathbf{A}_{2}$. Its maximal enzymatic hydrolysis is observed at melittin phospholipid ratios of about $1: 100^{8)} \cdot\left[1-^{14} \mathrm{C}\right]$ Arachidonic acid $(55.8 \mathrm{mCi} / \mathrm{mmol})$ was a New England Nuclear product.

\section{Preparation of Rat Liver Slice Labelled and Non-labelled with $\left[1-{ }^{14} \mathrm{C}\right]$ Arachidonic Acid}

Principally, by the method of $\AA$ Kesson et al. ${ }^{7)},\left[1-{ }^{14} \mathrm{C}\right]$ arachidonic acid, $9.45 \times 10^{5} \mathrm{dpm}$, was dissolved in $1 \mathrm{ml}$ hexane and stirred with $5 \mathrm{ml}$ of $10 \%$ bovine serum albumin solution in $0.1 \mathrm{~N} \mathrm{NaOH}, \mathrm{pH} 8.0$ for 20 minutes in a Ultra Turrax (IKA Werke Co., F.R.G.). The hypolayer was aspirated, $0.7 \mathrm{ml}$ of

\footnotetext{
† Present address: Department of The Third Division of Internal Medicine, Kansai Medical School
} 
which, $5.94 \times 10^{5} \mathrm{dpm}$, was injected into a portal vein of male Wistar rat (about $200 \mathrm{~g}$ ). The rat had been fasted for 24 hours and was anesthetized with pentobarbital $(50 \mathrm{mg} / \mathrm{kg})$. After 30 minutes, the liver was removed, washed with $0.9 \%$ saline and sliced with a slicer (Natsume, Japan). The diameter of the round slice was $26 \mathrm{~mm}$ and the wet weight about $100 \mathrm{mg}$, which contained about $150 \mu \mathrm{g}$ lipid-phosphorus. Non-labelled slice was prepared similarly without the administration of $\left[1-{ }^{14} \mathrm{C}\right]$ arachidonic acid. One slice was used for control and the others were for main experiments. When two or more rats were needed for an experiment, those who were similar in age and body weight were used.

\section{Assay System for the Endogenous Phospholipid Degradation in Liver Slice}

The slice was incubated in $2 \mathrm{ml}$ Hanks buffer, $\mathrm{pH} 7.2$, containing $N$-(2-hydroxyethyl)piperazine- $N^{\prime}-2$ ethylene sulfonic acid (HEPES), in a 50-ml glass stoppered tube for definite time intervals in the presence or absence of antibiotics. The slice was removed and the total lipids were extracted ${ }^{8)}$. The separation of simple lipids and phospholipids was carried out by column chromatography on silicic acid ${ }^{9)}$, and each component of phospholipids was separated by preparative thin-layer chromatography in a solvent mixture of $\mathrm{CHCl}_{3}-\mathrm{CH}_{3} \mathrm{OH}-\mathrm{H}_{2} \mathrm{O}(65: 35: 8)$, detected with Rhodamine $6 \mathrm{G}$, scraped off the plate, extracted and the phosphorus was determined.

The endogenous phospholipase activity was expressed by percentage decrease in lipid-phosphorus content of the slice. The inhibitory action of antibiotics on the enzymatic reaction was expressed as percent inhibition of the decrease in lipid-phosphorus of the slice. $\operatorname{ID}_{50}$ is the concentration of antibiotics which cause $50 \%$ inhibition of the decrease in phospholipid content of the slice during a 4-hour incubation period.

Liver Perfusion with Heat-treated Phospholipase $\mathrm{A}_{2}$, Melittin and Polymyxin B

Male Wistar rats (about $200 \mathrm{~g}$ ) were fasted for 24 hours and anesthetized with pentobarbital and perfused with Hanks buffer, pH 7.4, containing 10 mM HEPES at a flow rate of $30 \mathrm{ml}$ per 1 minute, according to the procedure of SEGLEN ${ }^{10)}$. The perfusate contained heat-treated phospholipase $\mathrm{A}_{2}$ (Crotalus adamanteus), melittin or antibiotics. After perfusion for definite time intervals, about $1 \mathrm{~g}$ liver tissue was removed from 5 different sites of the liver and phospholipids of each were analyzed.

\section{Results}

The Change in Phospholipid Content of Rat Liver Slice with Time

A typical degradation pattern of endogenous phospholipids in rat liver slice is shown in Fig. 1, and the distribution of radioactivity derived from $\left[1-{ }^{14} \mathrm{C}\right]$ arachidonic acid into simple lipids and phospholipids is presented in Fig. 2. Since the decrease in content and radioactivity of phospholipids was similar, nonlabelled slice was used in subsequent experiments.

Table 1. Inhibitory effect of some antibiotics on endogenous phospholipid degradation in rat liver slice.

\begin{tabular}{|c|c|c|c|c|}
\hline \multirow{3}{*}{ Antibiotics } & \multicolumn{4}{|c|}{$\begin{array}{l}\text { Remaining phospholipid content in liver slice } \\
\text { ( } \mu \mathrm{g} \text { lipid-phosphorus/g liver slice) }\end{array}$} \\
\hline & \multicolumn{4}{|c|}{ Concentration of antibiotics (mM) } \\
\hline & 0 & 3 & 5 & 10 \\
\hline Benzylpenicillin, $\mathrm{n}=5$ & & $76.0 \pm 4.8$ & $78.4 \pm 1.5$ & $77.4 \pm 4.8$ \\
\hline Carbenicillin, $\mathrm{n}=4$ & & $75.6 \pm 1.4$ & $73.0 \pm 2.7$ & $71.5 \pm 1.9$ \\
\hline Cephaloridine, $\mathrm{n}=5$ & & $72.5 \pm 2.9$ & $74.8 \pm 6.2$ & $75.8 \pm 8.7$ \\
\hline Chloramphenicol, $\mathrm{n}=6$ & & $77.4 \pm 2.4$ & $79.0 \pm 8.7$ & $82.7 \pm 4.7$ \\
\hline Streptomycin, $\mathrm{n}=4$ & & $66.6 \pm 3.7$ & $68.6 \pm 5.1$ & $72.8 \pm 3.7$ \\
\hline Polymyxin $\mathrm{B}, \mathrm{n}=5$ & & $92.0 \pm 4.3$ & $91.7 \pm 8.3$ & $92.8 \pm 2.9$ \\
\hline Peplomycin, $\mathrm{n}=3$ & & $74.3 \pm 2.5$ & $78.5 \pm 1.9$ & $77.1 \pm 3.7$ \\
\hline Tetracaine, $\mathrm{n}=3$ & & $80.0 \pm 7.1$ & $88.1 \pm 6.6$ & $94.9 \pm 3.0$ \\
\hline $\mathrm{EDTA} \cdot 2 \mathrm{Na}, \mathrm{n}=3$ & & $81.7 \pm 1.6$ & $89.0 \pm 6.1$ & $89.4 \pm 1.9$ \\
\hline Control, $\mathrm{n}=38$ & $72.3 \pm 5.1$ & & & \\
\hline
\end{tabular}


Fig. 1. The endogenous phospholipid degradation in rat liver slice with time.

The solid line indicates lipid-phosphorus, the dotted line ${ }^{14} \mathrm{C}$.

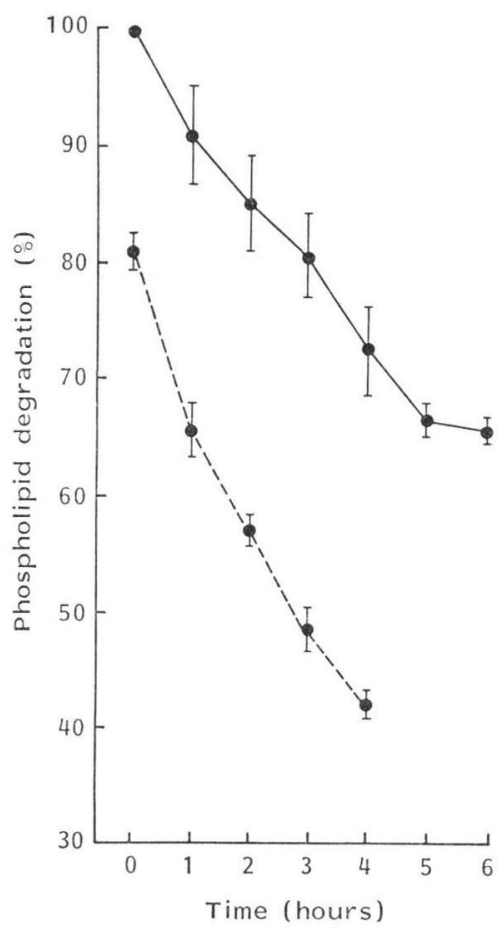

Fig. 2. The change in distribution of ${ }^{14} \mathrm{C}$ into simple lipids and phospholipids with time.

The radioactivity was derived from $\left[1-{ }^{14} \mathrm{C}\right]-$ arachidonic acid. The solid line indicates phospholipids, the dotted line simple lipids.

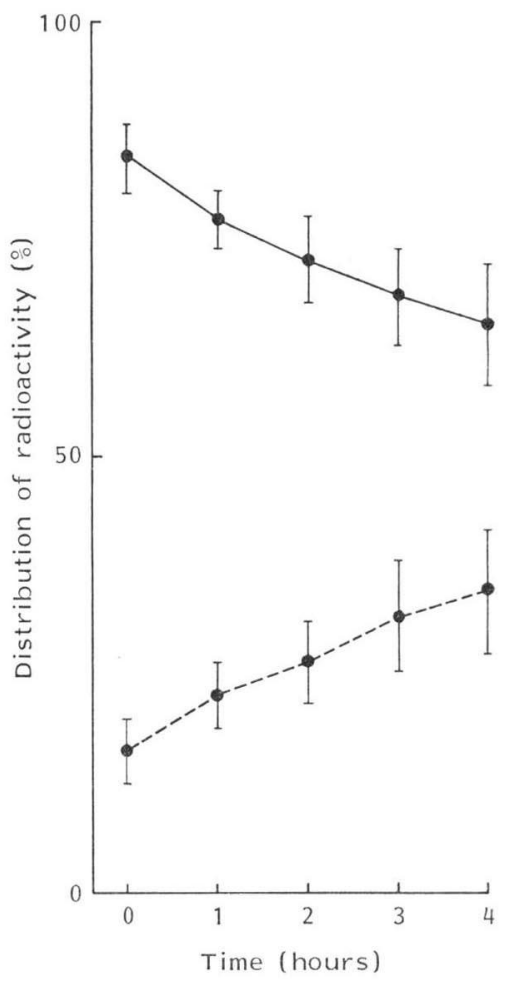

When the glass tube was filled with a $\mathrm{N}_{2}-\mathrm{CO}_{2}$ mixture (92:8), instead of air, no difference in degradation of endogenous phospholipids was observed. The liver tissue, on a slice level, might be not so sensitive to distinguish between the air and a $\mathrm{N}_{2}-\mathrm{CO}_{2}$ mixture.

The Effects of Antibiotics on Endogenous Phospholipid Degradation in Slice

Among the antibiotics tested, polymyxin B inhibited most strongly the endogenous phospholipid degradation, and benzylpenicillin, chloramphenicol and peplomycin inhibited moderately. Carbenicillin, cephaloridine and streptomycin, on the other hand, did not inhibit. Tetracaine, a local anesthetic, known as an inhibitor of phospholipase $A_{2}$ activity, showed a strong inhibitory effect on endogenous phospholipid degradation. EDTA inhibited the phospholipid degradation presumably owing to the chelation of $\mathrm{Ca}^{++}$, which is an essential factor for phospholipase $\mathrm{A}_{2}$ activity, but even at $10 \mathrm{~mm}$ concentration, the phospholipid degradation was not prevented completely (Table 1).

In case of benzylpenicillin, for example (Table 2), dose dependent inhibition was observed and similar results were also found in pancreas slice as reported elsewhere ${ }^{11}$.

\section{Effect of Polymyxin B on Melittin-induced Phospholipid}

Degradation at Liver Perfusion

Since some antibiotics, particularly polymyxin B, inhibited the endogenous phospholipid degrada- 
Table 2. Dose-dependent inhibition of benzylpenicillin on endogenous phospholipid degradation in rat liver slice.

\begin{tabular}{cc}
\hline $\begin{array}{c}\text { Concentration } \\
(\mathrm{mM})\end{array}$ & $\begin{array}{c}\text { Remaining phospholipids in } \\
\text { liver slice after 4-hour } \\
\text { incubation } \\
\text { ( } \mu \text { g lipid-phosphorus/g liver } \\
\text { slice) }\end{array}$ \\
\hline 1 & $73.7 \pm 4.4$ \\
3 & $76.0 \pm 4.8$ \\
5 & $78.4 \pm 1.5$ \\
10 & $77.4 \pm 4.8$ \\
20 & $82.2 \pm 6.3$ \\
30 & $89.0 \pm 5.4$ \\
\hline $\mathrm{n}=5$ & \\
\hline
\end{tabular}

Table 3. Effect of polymyxin B on melittin-induced phospholipid degradation.

\begin{tabular}{|c|c|c|}
\hline & Perfusate & $\begin{array}{l}\text { Remaining phospholipids } \\
\text { after perfusion for } 4 \text { hours } \\
\text { ( } \mu \mathrm{g} \text { lipid-phosphorus/g liver) }\end{array}$ \\
\hline 1) & Control & $1,327.2 \pm 108.7(100 \%)$ \\
\hline 2) & Melittin & $918.0 \pm 66.5(69 \%)$ \\
\hline 3) & Polymyxin B & $1,363.6 \pm 130.4(103 \%)$ \\
\hline
\end{tabular}

Fig. 3. The comparison in phospholipid composition of livers perfused with melittin and polymyxin $\mathrm{B}$ with control.

PE, PC, Sph and LPC, respectively stand for phosphatidylethanolamine, phosphatidylcholine, sphingomyelin and lysophosphatidylcholine.
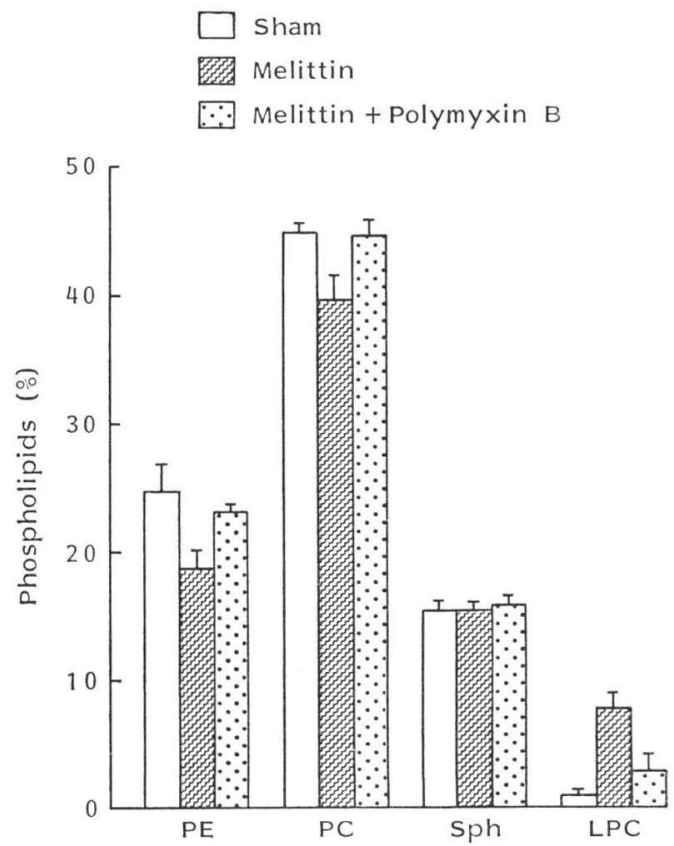

tion in liver slice, the inhibitory effect of polymyxin B was also examined at an organ level by perfusion. Perfusion with Hanks buffer alone did not show any phospholipid degradation. Even perfusion of heat-treated phospholipase $A_{2}$ in amounts of 807, 2,727 and 4,035 $\mu \mathrm{g}$ in $50 \mathrm{ml}$ Hanks buffer did not result in phospholipid degradation, although the latter dose should readily hydrolyze $50 \%$ of liver phospholipids theoretically in vitro. The reason why the exogenous phospholipase $\mathrm{A}_{2}$ did not work is not clear, but the molecule, MW 29,800, may be too large to pass through the capillary bed. However, by perfusing melittin, the endogenous phospholipids were degradated, and in this system the effect of polymyxin B was examined.

Three $130 \mathrm{~g}$ rat livers were perfused separately with 1) Hanks buffer for 30 minutes, 2) Hanks buffer for 5 minutes and then $2 \mathrm{mg}$ melittin in $50 \mathrm{ml}$ Hanks buffer for 20 minutes, and 3) $5 \mathrm{~mm}$ polymyxin B solution for 5 minutes and then $2 \mathrm{mg}$ melittin in $5 \mathrm{~mm}$ polymyxin B solution in Hanks buffer for 20 minutes. The molar ratio of $2 \mathrm{mg}$ melittin to the endogenous phospholipids in liver slice was about 1 : 460, which was smaller than the value, 1: 100, reported by Mollay et al. ${ }^{6)}$. As shown in Table 3, polymyxin B clearly inhibits the melittin-induced phospholipid degradation.

The phospholipid composition of perfused livers were analyzed by thin-layer chromatography. From melittin-treated liver lysophosphatidylcholine was found, but in the control experiment and in the case of melittin plus polymyxin B-treated livers the compound could not be detected (Fig. 3).

\section{Discussion}

The tentative hypothesis for pathogenesis of liver cell injury and death induced by hypoxic con- 
Fig. 4. The comparison in inhibitory action of antibiotics in term of $\mathrm{ID}_{50}$.

1, Carbenicillin; 2, cephaloridine; 3 , chloramphenicol; 4, streptomycin; 5 , polymyxin B; 6 , peplomycin; 7, tetracaine; 8, EDTA; 9, benzylpenicillin.
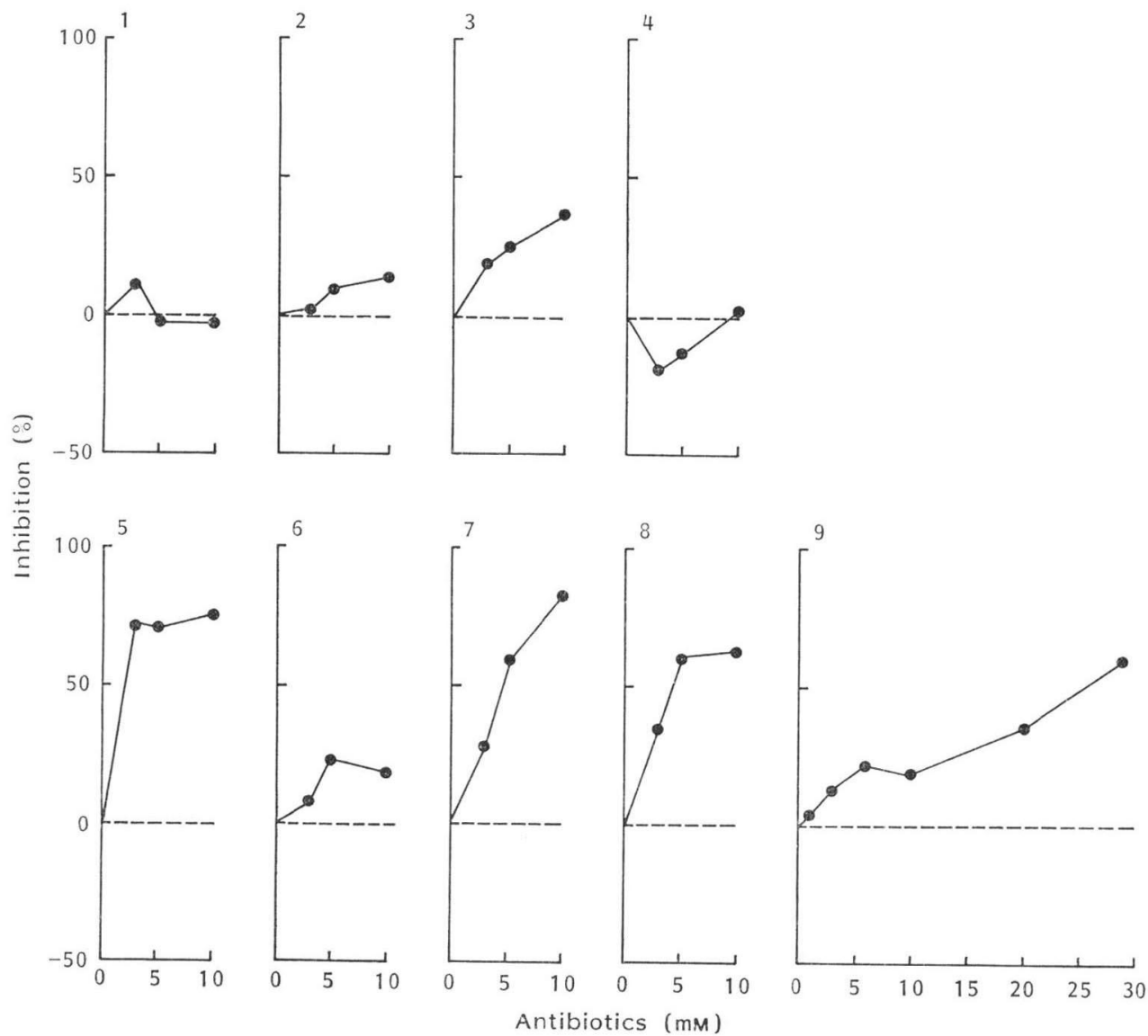

Table 4. Inhibitory effects of some antibiotics on endogenous phospholipid degradation of rat liver and pancreas.

\begin{tabular}{lcc}
\hline \multicolumn{1}{c}{ Antibiotics } & Liver & Pancreas \\
\hline Benzylpenicillin & + & +++ \\
Carbenicillin & - & +++ \\
Cephaloridine & - & $\mathrm{NT}$ \\
Tetracycline & $\mathrm{NT}$ & +++ \\
Chloramphenicol & + & $\mathrm{NT}$ \\
Streptomycin & - & $\mathrm{NT}$ \\
Polymyxin B & +++ & - \\
Peplomycin & + & $\mathrm{NT}$ \\
EDTA·2Na & ++ & $\mathrm{NT}$ \\
Tetracaine & +++ & +++ \\
Chlorpromazine & $\mathrm{NT}$ & +++ \\
\hline
\end{tabular}

NT: Not tested. ditions reckons with following events: Increase in the cell $\mathrm{Ca}^{++}$content, the activation of endogenous phospholipases, the creation of $\mathrm{Ca}$ channel, the inactivation of mitochondria, the denaturation of structural proteins, and finally cell death ${ }^{1)}$.

As shown in Fig. 4, some antibiotics tested, particularly polymyxin $\mathrm{B}$, inhibit the endogenous phospholipid degradation of rat liver under hypoxic conditions. The mechanism is certainly not simple, but polymyxin B may perturb the membrane phospholipids as a cationic amphiphilic compound and so disturb the interaction of phospholipases with the biomembrane phospholipids, whereas peplomycin and EDTA inhibit the endogenous phospholipase activity by chelating $\mathrm{Ca}^{++}$, which is essential for phospholipase activity particularly $\mathrm{A}_{2}$. 
Compared to our previous results on pancreas tissue (Table 4), the inhibitory effects of antibiotics on endogenous phospholipase activity were found not to be identical in both tissues, presumably owing to the difference in organ specificity.

The biomedical meaning of antibiotics is originally seen in their actions against microorganisms, but it should be emphasized from the observation mentioned above that some antibiotics prevented the endogenous phospholipid degradation of cells under hypoxic conditions and presumably maintain biological functions of biomembranes of host cells. From the stand point of the latter view, it is very suggestive that dogs, after ligation of their hepatic artery, die of ischemic liver necrosis within 2 or 3 days $^{12)}$. However, when they are treated with benzylpenicillin prior to ligation, they survive ${ }^{13 \sim 17}$.

On the other hand, it also must be noted that aminoglycoside antibiotics inhibit the lysosomal phospholipase $\mathrm{A}$ and $\mathrm{C}$ in liver ${ }^{18)}$ and kidney $^{19)}$, resulting in phospholipid accumulation or aminoglycoside toxicity such as nephrotoxicity. In relation to this, drug-induced lipid storage diseases by, for example, the coronary vasodilator, 4,4'-bis-(diethylaminoethoxy)- $\alpha, \beta$-diethyldiphenylethan ${ }^{20)}$, and amphiphilic cationic drugs ${ }^{21)}$ are reported and the possible metabolic explanation is the inhibition of phospholipase activity by drugs ${ }^{21)}$.

\section{Acknowledgments}

The authors wish to express their thanks to Dr. I. Honso in our medical school for his valuable discussion and to Dr. T. OKumuRA in our group for his skillful technical assistance in liver perfusion. This work was supported in part by Grant-in-Aid for Scientific Research from The Ministry of Education, Science and Culture in Japan and also in part by The Naito Foundation Research Grant for 1983.

\section{References}

1) Chien, K. R.; J. Abrams, A. Serroni, J. T. Martin \& J. L. Farber: Accelerated phospholipid degradation and associated membrane dysfunction in irreversible ischemic liver cell injury. J. Biol. Chem. 253: $4809 \sim 4817,1978$

2) Smith, M. W.; Y. Collan, M. W. Kahng \& B. F. Trump: Change in mitochondrial lipids of rat kidney during ischemia. Biochim. Biophys. Acta 618: 192 201, 1980

3) SAITO, K.; Y. OKADA \& N. KAWASAKI: Inhibitory effect of some antibiotics on phospholipases. J. Biochem. 72: $213 \sim 214,1972$

4) Sugatani, J.; K. Saito \& I. Honjo: In vitro actions of some antibiotics on phospholipases. J. Antibiotics 32: 734 739, 1979

5) SaIto, K. \& D. J. Hanahan: A study of the purification and properties of the phospholipase A of Crotalus adamanteus venom. Biochemistry 1: $521 \sim 532,1962$

6) Mollay, C.; G. Kreil \& H. Berger: Action of phospholipases on the cytoplasmic membrane of Escherichia coli. Biochim. Biophys. Acta 426: 317 324, 1976

7) Åkesson, B.; J. Elovson \& G. Arvidson: Initial incorporation into rat liver glycerolipids of intraportally injected $\left[9,10-{ }^{3} \mathrm{H}_{2}\right]$ palmitic acid. Biochim. Biophys. Acta 218: 44 56, 1970

8) Bligh, E. G. \& W. J. Dyer: A rapid method of total lipid extraction and purification. Can. J. Biochem. Physiol. 37: 911 917, 1959

9) Hanahan, D. J.; J. C. Dittmer \& E. Warashina: A column chromatographic separation of classes of phospholipids. J. Biol. Chem. 228: 685 700, 1957

10) Seglen, P. O.: Preparation of isolated rat liver cells. Meth. Cell Biol. 13: 29 83, 1976

11) TanaKa, T.: Studies on phospholipid metabolism of pancreas under hypoxic conditions and influence of antibiotics. Arch. Jap. Chir. 16: 1510 1519, 1983 (In Japanese)

12) Haberer, H.: Experimentelle Unterbindung der Leberaterie. Arch. f. Klin. Chir. 78: 557 587, 1906

13) Markowitz, J.; A. M. Rappaport \& A. C. Scott: Prevention of liver necrosis following ligation of hepatic artery. Proc. Soc. Exp. Biol. Med. 70: 305, 1949

14) Honjo, I.: Surgery of Liver, Pancreas and Bile Duct. Nankodo, Kyoto, 1980 (In Japanese)

15) Grindlay, J. H.; F. C. Mann \& J. L. Bollman: Effect of occlusion of the arterial blood supply to the normal liver. Arch. Surg. 62: 806 811, 1951

16) Fraser, D.; A. M. Rappaport, C. A. Vuylsteke \& A. R. Colwell: Effect of the ligation of the hepatic artery in dogs. Surgery 30: 624 641, 1951 
17) Matsumoto, J.; T. Tanaka, M. Gamo, K. Saito \& I. Honjo: Phospholipid metabolism of dog liver under hypoxic conditions induced by ligation of the hepatic artery. Biochim. Biophys. Acta 664: 527 537, 1981

18) Hostetler, K. Y. \& L. B. Hall: Aminoglycoside antibiotics inhibit lysosomal phospholipase A and C from rat liver in vitro. Biochim. Biophys. Acta 710: 506 509, 1982

19) Hostetler, K. Y. \& L. B. Hall: Inhibition of kidney lysosomal phospholipase A and C by aminoglycoside antibiotics: Possible mechanism of aminoglycoside toxicity. Proc. Natl. Acad. Sci. USA, Biol. Sci. 79: $1663 \sim 1667,1982$

20) Yamamoto, A.; S. Adachi, T. Kitani, Y. Shinji, K. Seki, T. Nasu \& M. Nishikawa: Drug-induced lipidosis in human cases and in animal experiments, accumulation of an acidic glycerophospholipid. J. Biochem. 69: 613 615, 1971

21) Michell, R. H.; D. Allan, M. Bowley \& D. N. Brindley: A possible metabolic explanation for druginduced phospholipidosis. J. Pharm. Pharmacol. 28: 331 332, 1976 